\title{
Nonmatching- (oddity) and delayed nonmatching-to-sample performance in aging, alcoholic, and alcoholic Korsakoff individuals
}

\author{
MARLENE OSCAR-BERMAN and ROBERT T. BONNER \\ Boston Veterans Administration Medical Center \\ and Boston University School of Medicine, Boston, Massachusetts
}

\begin{abstract}
Measures of visual processing time, selective attention, and memory were obtained in 59 normal and alcoholic research participants (including 13 with alcoholic Korsakoff's syndrome) ranging in age from 35 to 71 years. Performance was measured within the context of nonmatching-tosample and delayed nonmatching-to-sample tasks. The tasks required the participants to identify the "odd" stimulus in a three-stimulus array (i.e., to choose one of two laterally located visual stimuli that did not appear as a central sample display). The sample stimulus varied in complexity, containing one or two stimulus dimensions (color and/or line tilt), and exposure duration of the sample stimulus varied from 20 to $500 \mathrm{msec}$. The interval between sample offset and response opportunity also was varied, from 0 to $30 \mathrm{sec}$. The results indicated that for all groups, simple (unidimensional) sample stimuli were easier than compounds (two dimensions), as were stimuli that were available for long durations and with short interstimulus delays. Duration of the sample's exposure and the delay between sample and response choice were the variables that best differentiated among the groups. With short sample durations and at long delay intervals, the Korsakoff patients were the least accurate. Although older participants-regardless of their drinking history-also were impaired, the age-group differences were exaggerated in the alcoholics. The results emphasize the importance of processing deficits in amnesia of alcohol-related etiology, and in the cognitive decline that may accompany aging and alcoholism.
\end{abstract}

A primary aim of the present study was to extend the generality of previous findings of visual processing and attentional deficits in patients with anterograde amnesia associated with alcoholic Korsakoff's disease (see Ellis \& Oscar-Berman, 1989; Oscar-Berman \& Ellis, 1987; and Ryan \& Butters, 1987, for recent reviews of the literature). A second goal of the present research was to test the "premature aging hypothesis" of alcoholism, that is, that alcohol abuse intensifies or accelerates age-related changes in cognition (Ellis \& Oscar-Berman, 1988; Parsons, 1987; Ryan \& Butters, 1986; Wilkinson \& Carlen, 1982). To these ends, we attempted to parcel out any differential contributions of alcoholism and normal chronological aging to deficits in processing, attention, and memory. We conducted a nonmatching-to-sample (NMTS) and delayed nonmatching-to-sample (DNMTS) study in which performance by alcoholic and normal individuals was compared across a wide age span. The tasks have

\footnotetext{
Support for this research came from the Medical Research Service of the Veterans Administration and from the following USDHHS grants: NLAAAA AA07112, AA05211, and RSDA AA00061; and NINCDS NSO6209. Appreciation goes to Mary Hyde for statistical help, and to F. Robert Treichler for his very helpful advice. Address reprint requests to Marlene Oscar-Berman, BVAMC (116B), 150 South Huntington Avenue, Boston, MA 02130.
}

been used successfully for disclosing behavioral impairments in monkeys with damage to brain structures implicated in human amnesia (e.g., see Horel, 1978, for review; Squire, Zola-Morgan, \& Chen, 1988).

The NMTS and DNMTS tasks employed in the present study required participants to choose the "odd one" from an array of three stimuli: one centrally located stimulus (the sample) was displayed in the middle between two others (serving also as response choices). Temporal duration of the sample stimulus was varied, as was its complexity (the number of stimulus dimensions) and the delay between stimulus components needed for solution. With a delay interposed between sample and choice stimuli, accuracy was dependent upon two forms of memory: memory for the rule of the task ("semantic" or "procedural" memory) and memory for information displayed just prior to the delay on each trial ("episodic" or "declarative" memory) (see Tulving, 1985). Thus, we were able to measure the interactions of semanticl procedural memory with temporal requirements for stimulus processing, attention to single versus compound visual cues, and demands upon short-term (episodic/declarative) memory.

Work with alcoholic Korsakoff (amnesic) patients has confirmed that there are simultaneous deficits in numerous facets of their perceptual and cognitive abilities (Ellis 
\& Oscar-Berman, 1989; Oscar-Berman, 1984; Warrington \& Weiskrantz, 1974). These deficits have been related to widespread brain damage including diencephalic and basal forebrain structures, the Papez circuit, and the neocortex, especially in the frontal and temporal lobes (Arendt, Bigl, Arendt, \& Tennstedt, 1983; Butters, 1987; Horel, 1978; Lhermitte \& Signoret, 1976; Oscar-Berman, 1984; Squire et al., 1988; Witt \& Goldman-Rakic, 1983). In the present study, associative learning was held relatively constant by keeping task demands easy; all participants were required to learn the NMTS strategy to a high criterion level of performance (approximately $90 \%$ ) prior to being given the DNMTS tasks. What was manipulated was the interaction of demands upon episodic memory, perceptual processing, and the ability to attend to and analyze several stimulus parameters. It was reasoned that impairments in episodic memory should be manifested as decreases in DNMTS performance levels with increasing delays between sample and choice stimuli. Perceptual processing deficiencies would be manifested as poorer performance with short as compared with long sample-stimulus durations. Deficits in attention would be manifested in relatively greater error scores with compound than with simple stimulus dimensions. Regardless of the pattern of results, however, additional knowledge would be gained about aging, alcoholism, and amnesia.

\section{MATERIALS AND METHOD}

\section{Subjects}

A total of 59 male volunteers comprised seven separate groups as follows: 7 young normals (YN) and 7 young alcoholics (YA), 35-45 years old; 7 middle-aged normals (MN) and 11 middle-aged alcoholics (MA), 46-59 years old; 7 older normals (ON) and 7 older alcoholics (OA), 60-69 years old; and a separate group of 13 alcoholic Korsakoff patients (K), 41-71 years old. Additional subject variables are listed in Table 1. Participants were selected from neurology, psychiatry, general medical, out-patient, and hospital volunteer services of the Boston Veterans Administration Medical Center, and from rehabilitation facilities around the Boston area (Mount Pleasant Hospital, Framingham Rehabilitation Hospital, and several VA-affiliated residential homes). The subjects had participated in an earlier study (Oscar-Berman \& Bonner, 1985).

Exclusion criteria for all the participants included a history of epilepsy or of head injury requiring hospitalization, major psychiatric disease (e.g., schizophrenic disorders and primary depression),

Table 1

The Seven Groups of Participants in the Study

\begin{tabular}{|c|c|c|c|c|c|c|}
\hline & Age & $\begin{array}{l}\text { Years of } \\
\text { Education }\end{array}$ & $\begin{array}{c}\text { Verbal IQ } \\
\text { (VIQ) }\end{array}$ & $\begin{array}{c}\text { Memory Quotient } \\
\text { (MQ) }\end{array}$ & $\begin{array}{l}\text { VIQ-MQ } \\
\text { Difference }\end{array}$ & $\begin{array}{c}\text { Years of } \\
\text { Alcohol Use }\end{array}$ \\
\hline \multicolumn{7}{|c|}{ Young Normals (7) } \\
\hline $\begin{array}{l}M \\
S D \\
\text { Range }\end{array}$ & $\begin{array}{c}41 \\
3.1 \\
35-45\end{array}$ & $\begin{array}{r}12.4 \\
1.9 \\
9-14\end{array}$ & $\begin{array}{c}104.6 \\
7.5 \\
95-116\end{array}$ & $\begin{array}{c}108.0^{*} \\
16.2 \\
93-141\end{array}$ & $\begin{array}{c}-3.4^{*} \\
9.8 \\
-25 \text { to }+4\end{array}$ & \\
\hline \multicolumn{7}{|c|}{ Middle Normals (7) } \\
\hline $\begin{array}{l}M \\
S D \\
\text { Range }\end{array}$ & $\begin{array}{c}56 \\
3.0 \\
52-59\end{array}$ & $\begin{array}{r}11.3 \\
3.9 \\
4-16\end{array}$ & $\begin{array}{c}118.6 \\
14.2 \\
97-136\end{array}$ & $\begin{array}{c}125.7^{*} \\
18.7 \\
100-143\end{array}$ & $\begin{array}{c}-7.1^{*} \\
9.3 \\
-17 \text { to }+10\end{array}$ & \\
\hline \multicolumn{7}{|c|}{ Older Normals (7) } \\
\hline $\begin{array}{l}M \\
S D \\
\text { Range }\end{array}$ & $\begin{array}{c}65 \\
3.0 \\
60-69\end{array}$ & $\begin{array}{r}12.6 \\
1.0 \\
12-14\end{array}$ & $\begin{array}{c}115.6 \\
14.7 \\
107-148\end{array}$ & $\begin{array}{c}109.0^{*} \\
16.1 \\
95-143\end{array}$ & $\begin{array}{c}6.6^{*} \\
3.7 \\
+3 \text { to }+14\end{array}$ & \\
\hline \multicolumn{7}{|c|}{ Young Alcoholics (7) } \\
\hline $\begin{array}{l}M \\
S D \\
\text { Range }\end{array}$ & $\begin{array}{c}41 \\
3.8 \\
35-45\end{array}$ & $\begin{array}{r}12.1 \\
2.0 \\
9-15\end{array}$ & $\begin{array}{c}107.7 \\
8.3 \\
95-118\end{array}$ & $\begin{array}{c}106.9^{*} \\
14.3 \\
87-124\end{array}$ & $\begin{array}{c}0.8^{*} \\
9.4 \\
-8 \text { to }+12\end{array}$ & $\begin{array}{c}12.9 \dagger \\
4.9 \\
7-22\end{array}$ \\
\hline \multicolumn{7}{|c|}{ Middle Alcoholics (11) } \\
\hline $\begin{array}{l}M \\
S D \\
\text { Range }\end{array}$ & $\begin{array}{c}52 \\
5.4 \\
46-59\end{array}$ & $\begin{array}{r}11.7 \\
2.1 \\
9-14\end{array}$ & $\begin{array}{c}108.2 \\
9.7 \\
94-126\end{array}$ & $\begin{array}{c}110.8 * \\
10.9 \\
90-126\end{array}$ & $\begin{array}{c}-2.6 * \\
11.9 \\
-21 \text { to }+15\end{array}$ & $\begin{array}{c}20.1 \\
8.3 \\
10-37\end{array}$ \\
\hline \multicolumn{7}{|c|}{ Older Alcoholics (7) } \\
\hline $\begin{array}{l}M \\
S D \\
\text { Range }\end{array}$ & $\begin{array}{c}62 \\
2.2 \\
60-65\end{array}$ & $\begin{array}{r}10.9 \\
3.0 \\
5-14\end{array}$ & $\begin{array}{c}110.1 \\
6.4 \\
106-123\end{array}$ & $\begin{array}{c}104.0^{*} \\
9.9 \\
93-117\end{array}$ & $\begin{array}{c}6.1^{*} \\
7.3 \\
-5 \text { to }+13\end{array}$ & $\begin{array}{c}25.4 \\
11.3 \\
13-41\end{array}$ \\
\hline \multicolumn{7}{|c|}{ Korsakoffs (13) } \\
\hline $\begin{array}{l}M \\
S D \\
\text { Range } \\
\end{array}$ & $\begin{array}{c}55 \\
8.4 \\
41-71 \\
\end{array}$ & $\begin{array}{r}11.7 \\
2.9 \\
8-19 \\
\end{array}$ & $\begin{array}{r}109.3 \\
15.6 \\
87-139 \\
\end{array}$ & $\begin{array}{c}79.0 \\
12.2 \\
59-97 \\
\end{array}$ & $\begin{array}{c}30.3 \\
9.2 \\
+21 \text { to }+47\end{array}$ & $\begin{array}{l}\text { Unk } \\
\text { Unk } \\
\text { Unk }\end{array}$ \\
\hline
\end{tabular}

Note-Numbers in parentheses indicate the number of subjects in each group. Mean ages are given in years. All significant group differences listed here are indicated in the table (Scheffé test for multiple comparisons; Winer, 1979). *Significantly different from Korsakoffs $(p<.05)$. †Significantly different from Older Alcoholics $(p<.05)$. 
ECT, diabetes, polydrug abuse, and clinical evidence of active hepatic disease. This information was obtained from a variety of sources including hospital records, consultation with referral sources, and interviews with the potential research participants. An additional requirement for the alcoholic groups (including $\mathrm{Ks}$ ) was that they be detoxified for at least 1 month prior to testing, in order to ensure stable levels of alcohol-free performance (NIAAA, 1983). The alcoholics were asked to participate in the study if they had met the DSM III criteria for alcohol dependence (e.g., need for daily use, inability to decrease consumption, impairment in social or occupational functioning, etc.). To assess pattern-of-drinking history, we used a modification of the questionnaire described by Cahalan, Cisin, and Crossley (1969) and MacVane, Butters, Montgomery, and Farber (1982). The information obtained from this questionnaire was validated by comparison to information obtained from medical records, and from interviews with staff of the medical and rehabilitation facilities serving as referral sources. In addition, the Ks were diagnosed by the psychology and neurology services of the Boston VA Medical Center, and had an IQ within normal range and a discrepancy of at least 20 points between WAIS verbal-IQ scores and Wechsler Memory Scale memory quotients (MQ). No non-Korsakoff alcoholic was included if he showed clinical signs of memory impairment or had a spread of more than 15 points between verbal-IQ and MQ scores. As indicated in Table 1, intergroup MQ differences were significant only between the $\mathrm{Ks}$ and each of the other groups. Informed consent was obtained during an initial interview conducted prior to formal testing, and participants received monetary compensation as part of the study (see Procedure).

\section{Apparatus and Stimuli}

The apparatus was described in a previous report (Oscar-Berman \& Bonner, 1985). We used a microprocessor (National Semiconductor) to run an automated Human Test apparatus (Technical Services, Inc.) equipped with three circular stimulus-response keys (diameter $2.54 \mathrm{~cm}$ ) and a coin dispenser. Stimuli were projected onto the keys from behind, and consisted of solid colors and/or white lines differing in orientation. Sample stimuli appeared on the center key, and stimulus choices for nonmatching (oddity) appeared on the two side keys. The sample stimuli (center key) were of two types; simple elements or compounds. The element sample stimuli consisted of one of two colors (red or green) or one of two sets of achromatic lines (with vertical or horizontal orientations). Compound sample stimuli were composed of lines superimposed on a colored background. The comparison stimuli (side keys) were never compounded; either the two colors or the two sets of achromatic lines appeared together on the side keys. Likewise, when the sample stimulus was a compound, the two comparisons again were either two colors or two sets of lines.

\section{Procedure}

The procedure was modeled after that described by Maki and Leith (1973) for matching-to-sample (MTS) and DMTS. Each trial began with the illumination of the center key with the letter " $X$ " against a white background. On NMTS trials, when a subject pressed the lighted center key with the $\mathrm{X}$ on it, he immediately was presented with the sample stimulus in place of the $X$, as well as with two comparison (choice) stimuli located to the left and right of the sample. On DNMTS trials, a response to the center $(X)$ key resulted immediately in the replacement of the $\mathrm{X}$ by a sample stimulus. Then, after a specified time period (i.e., one of the five durations of the sample stimulus as noted below), the center key was darkened and the side keys were illuminated with comparison stimuli. On NMTS and DNMTS trials alike, a correct response was defined as a response to the side key not containing the color or line orientation that appeared in the sample. Correct responses immediately turned off the stimuli and resulted in reinforcement and a 5-sec ITI. Incorrect responses were followed by a brief tone $(4500 \mathrm{~Hz}$ for
$0.26 \mathrm{sec}$ ) and delayed the offset of stimuli by $2 \mathrm{sec}$. Pennies served as reinforcements, but a penny was worth five cents, to be "traded in" at the end of each session.

The participants received a minimum of 24 NMTS trials and 120 training trials for DNMTS. The duration of the sample stimulus during NMTS trials was as long as needed. Duration of sample stimuli during DNMTS trials was controlled for $20,40,80,120$, or $500 \mathrm{msec}$. All trials were randomized for position of comparison stimuli, duration of sample, and number of dimensions in the sample, such that single and compound samples appeared at each duration, and each of four cues (two per dimension) appeared an equal number of times for responding. Delay intervals (for DNMTS) of $0,3,6,12,18$, and $30 \mathrm{sec}$ were then interposed between sample offset and onset of the comparison stimuli, and the subjects were given 120 trials for each delay condition. Accuracy was recorded automatically for every trial.

The participants were shown the apparatus and given instructions that were detailed in a previous report (Oscar-Berman \& Bonner, 1985). Briefly, they were told that they were going to play a game in which they could earn money by pressing the keys on the apparatus. Furthermore, when an " $X$ " appeared on the center key, pressing it would present them with a problem that could be solved by pressing either the left or the right key. They were also told that although the coin dispenser delivered only pennies, they would receive five cents for each penny earned with each correct response, and a tone would signal each error. The experimenter completed one correct and one incorrect response to show that a side-key response would turn off all three stimuli, and to demonstrate the operation of the coin dispenser and the tone generator (for incorrect responses). The experimenter then watched while the subject completed one correct and one incorrect response. As indicated above, there were 24 such training trials (with the upper limit of the stimulus exposure duration being defined by a subject's response latency). If the participant obtained 21 or more correct responses in the 24 trials, the study moved on to the phase with limited stimulus duration; if he made 20 or fewer correct responses, the same test was repeated until the learning criterion was reached. (No one required more than 120 trials to reach the criterion.)

Next, in preparation for DNMTS, limited stimulus duration was introduced as a transitional procedure. Instructions to the subjects indicated that the task was going to be repeated (all three stimuli coming on together), with the exception that the middle of the three keys might not stay on as long as the left and right keys. The subjects were told that in some cases, the middle key would be on for so short a time that they might think that they had not seen it at all; however, it would still be possible to earn a coin with each correct press of the side key. They were encouraged to earn as many coins as they could. After the experimenter demonstrated two practice trials, the subject was given 120 test trials. If the subject achieved a level of $88 \%$ or more correct responses on any two of the five stimulus durations, on both simple and compound stimuli, he was advanced to DNMTS with a 0-sec delay. One subject $(K)$ failed to reach this criterion after three blocks of NMTS testing ( 360 trials), and the exposure ceiling was raised from 500 to $750 \mathrm{msec}$ (dropping the 20-msec exposure duration). The same subject again failed to reach the criterion, and the exposure ceiling again was raised, to $1,000 \mathrm{msec}$, with the 40 - $\mathrm{msec}$ duration being dropped. The range of sample durations derived by this procedure $(80$ to $1,000 \mathrm{msec})$ was used with that subject for the remainder of the experiment.

Instructions for the 0-sec DNMTS were introduced as follows: "This problem is very similar to the one you just did. Would you like a review of the instructions?" (Review.) "It will take about 20 min to do it." The subsequent DNMTS tests contained 3-, 6-, $12-, 18-$, and 30-sec delays, respectively, and with each increasing delay, the participants were told that the only difference between this problem and the one just completed is that there would be a (longer) delay between when the middle key went off and when 
the side keys came on. An estimate of the length of the testing session also was provided; depending upon the delay condition, this could be about $30 \mathrm{~min}, 45 \mathrm{~min}, 1 \mathrm{~h}$, or $1.5 \mathrm{~h}$.

\section{RESULTS}

Two-way analyses of variance (ANOVAs) were performed with the NMTS data (group $\times$ dimension); fourway ANOVAs of the DNMTS data included the two additional factors of delay and duration. In the NMTS analyses of errors to criterion, there were no significant group effects. Thus, all of the groups were equally capable of learning the NMTS strategy. There was a significant main effect of dimension in NMTS $[F(1,52)=11.94, p<$ $.001]$, showing that, for everyone, simple-element stimuli were easier than compound stimuli.

Figures 1 and 2 summarize the DNMTS results. Because of the wide variability in the data obtained with the $\mathrm{Ks}$ in this phase of testing, the ANOVAs were performed separately on two sets of data compiled from different subgroupings of the subjects, according to age and diagnos- tic category. Thus, one set of ANOVAs was performed on the data obtained from three age-matched subgroups (13 subjects each) of non-Korsakoff alcoholics (As, mean age 55 years, range 41-65); normal controls (Ns, mean age 55 years, range 41-69); and Korsakoff patients (Ks, mean age 55 years, range 41-71). The data for these subjects are depicted in Figure 1. Another set of ANOVAs compared the data obtained from the six subgroups of agematched non-Korsakoff alcoholics and normal subjects (see Figure 2). The findings from the different subgroupings are reported separately.

\section{Korsakoff Patients Compared with} Age-Matched Normals and Non-Korsakoff Alcoholics

When comparing the performance of Ks with that of Ns and As equated for age, all of the main effects were statistically significant as follows: stimulus duration $[F(1,144)=96.40, p<.001]$, stimulus dimension $[F(1,36)=6.39, p<.02]$, delay $[F(5,180)=3.61, p<$ $.01]$, and group $[F(2,36)=8.76, p<.001]$. Thus, long stimulus durations facilitated performance, one stimulus

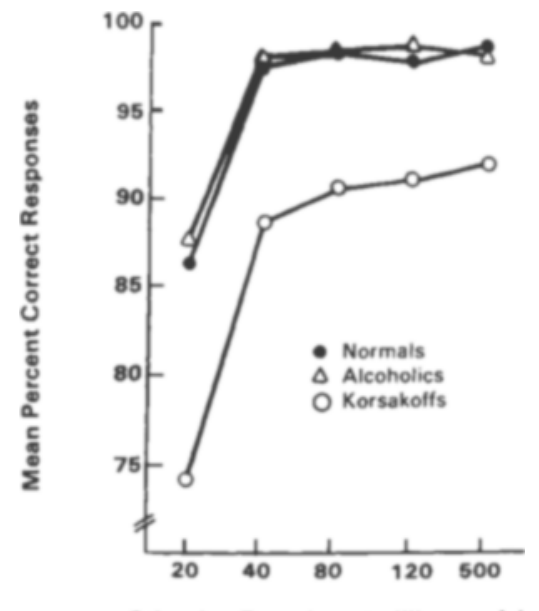

Stimulus Durations (milliseconds)

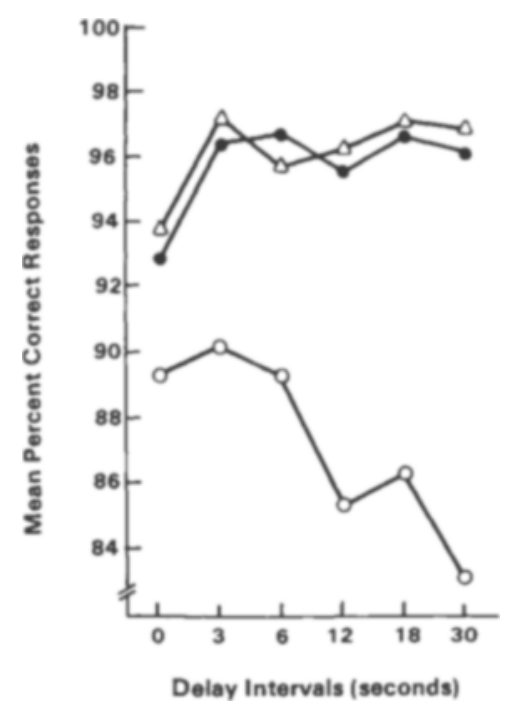

Figure 1. Percentage of correct responses on delayed nonmatching-to-sample with simpleelement and compound stimuli combined. The performance of three age-matched groups of subjects is shown across sample-stimulus durations (left) and delay conditions (right).
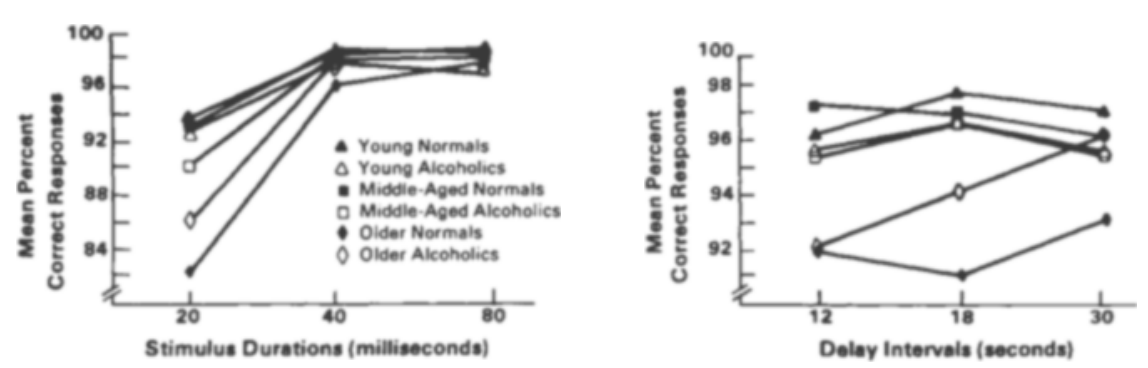

Figure 2. Percentage of correct responses on delayed nonmatching-to-sample with simple-element and compound stimuli combined. The performance of six subgroups (non-Korsakoff alcoholics and normal controls in three age ranges) is shown for three stimulus durations (left) and three delay conditions (right). 
dimension was easier than two, long delays between sample and choice stimuli disrupted performance, and the groups were not equal in their overall proficiency on the DNMTS tasks. In addition, the significant interactions of stimulus dimension $\times$ duration $[F(4,144)=3.52, p<$ $.01]$ and delay $\times$ duration $[F(20,720)=4.96, p<.001]$ indicated that briefly exposed samples were especially difficult when the stimuli were complex and when the delays were long (relative to simple stimuli and short delays). Furthermore, two interactions involving the subject groups were significant: group $\times$ stimulus duration $[F(8,144)=2.15, p<.05]$ and group $\times$ delay $[F(10,180)=4.24, p<.001]$. As indicated by post hoc comparisons among the groups, the Ks were significantly impaired relative to the Ns at all of the stimulus durations [ts(78) between 1.74 and 3.17, $p \mathrm{~s}<.05]$, and the Ks were worse than the As at all but the 500 -msec exposure duration $[t \mathrm{~s}(78)$ between 1.97 and 3.50 , $p$ s $<.05]$. Likewise, the Ks were significantly impaired relative to the Ns with all interstimulus delays of $6 \mathrm{sec}$ and above [ $t \mathrm{~s}(65)$ between 1.94 and 3.40, ps $<.05]$, and were worse than the As with delays of $3 \mathrm{sec}$ and above [ts(65) between 1.67 and $3.59, p \mathrm{~s}<.05$ ]. No significant differences between the As and the Ns were observed for any of the stimulus durations or for any of the delay intervals.

\section{Non-Korsakoff Alcoholics Compared with Age-Matched Normals}

There was considerable overlap among the six subgroups for the easiest conditions (i.e., long stimulus durations and short delays between sample and choice stimuli). Therefore, analyses were performed only on the data obtained with the more difficult conditions (i.e., the shortest stimulus durations-20, 40 , and $80 \mathrm{msec}-$ and the longest delays $-12,18$, and $30 \mathrm{sec}$ ). These results are summarized in Figure 2.

There was a significant main effect for stimulus dimension $[F(1,40)=21.51, p<.001]$ and for stimulus duration $[F(2,80)=41.09, p<.001]$, as well as a significant two-way interaction of stimulus dimension $X$ stimulus duration $[F(2,80)=17.02, p<.001]$. Thus, complex sample stimuli overall were more difficult than simple stimuli, and shorter durations interfered with performance more than did the long durations, especially when the stimuli were complex. The main effect of age also was significant $[F(2,40)=3.62, p<.05]$, as were the interactions of age $\times$ stimulus duration $[F(4,80)=$ $3.72, p<.01]$ and age $\times$ alcoholism $\times$ stimulus duration $\times$ delay $[F(8,160)=2.27, p<.05]$. Thus, in general, there was a negative relationship between aging and performance, which was intensified by the requirement of brief stimulus exposures. Furthermore, as the demands of short exposures and long delays were superimposed, the subgroups began to diverge in DNMTS ability.

Post hoc comparisons were performed in order to specify the nature of the group differences. These differ- ences were systematic in that older subjects performed more poorly than younger subjects; in Figure 2, this finding is obvious. Not obvious in Figure 2 is the finding that the performance differences related to age were more exaggerated for the alcoholics than for the normal subgroups. Thus, although the young and middle-aged alcoholics performed the DNMTS tasks significantly better than did the old alcoholics $[t(12)=11.60, p<.01$, and $t(16)=2.46, p<.05$, respectively], the difference between younger and older normal subgroups only approached significance $[t(12)=1.74, .05<p<.10]$, and there was no reliable difference between the middleaged and older normals $[t(16)=1.26, p>.10]$. The reason that the compounding effect of alcoholism and aging is not apparent in Figure 2 is that the effect was small and the intergroup comparisons were based upon combined data for the three shortest durations and the three longest delays.

In summary, it is clear that the Ks showed the greatest impairments. They were significantly impaired under virtually all experimental conditions beyond the easiest. Excluding Ks, the older subgroups of subjects-with and without a history of alcoholism-also showed some impairments, but the impairments were apparent only under the most difficult experimental conditions. Finally, presence of a history of alcoholism was not a major factor, but it did contribute somewhat to the age-group differences.

\section{DISCUSSION}

In an earlier study (Oscar-Berman \& Bonner, 1985), we employed the same visual and temporal parameters as those described in the present experiment; however, the subjects were required to match the sample (center) and choice (side) stimuli (matching- and delayed matching-to-sample) rather than to choose the odd one of the three. The results of both the earlier study and the present one are strikingly similar. Most importantly, all of the subjects were capable of learning the tasks' solutions (MTS as well as NMTS); that is, they were able to recognize and remember which cues were relevant and whether the cues were simple (unidimensional) or compounded.

The results of the present study confirm other findings of retarded visual processing in Ks and in elderly individuals (Oscar-Berman, 1980; Oscar-Berman \& Bonner, 1985; Oscar-Berman \& Weinstein, 1985; Schlotterer, Moscovitch, \& Crapper-McLachlan, 1984). Comparisons among the three age-matched normal, alcoholic, and Korsakoff groups indicated that the Ks were the least accurate of the participants, especially when sample-stimulus durations were brief and delays between stimulus offset and response opportunity were long. The delay condition was an excellent intergroup discriminator, showing deterioration by the $\mathrm{Ks}-$ in the face of steady levels of performance by the other groups-over increased delay inter- 
vals. By contrast, stimulus duration was not as effective as delay in discriminating among the groups; all groups improved with increased exposure times.

The significant age main effect in the six-group comparison (three age groups each of alcoholics and normals) was made up of a variety of contributing factors. Thus, there was a significant age $\times$ duration interaction, indicating that in older people, regardless of their drinking history, a critical variable in determining their level of performance was the amount of time available for processing the visual information. The importance of this variable has been stressed in a number of previous studies (Ellis \& Oscar-Berman, 1989; Oscar-Berman \& Bonner, 1985; Oscar-Berman \& Ellis, 1987; Oscar-Berman, Goodglass, \& Cherlow, 1973; Oscar-Berman \& Weinstein, 1985).

As evidenced by the significant main effects of stimulus dimension and stimulus duration (and dimension $x$ duration interactions), short stimulus durations and compound stimuli were more difficult than long stimulus durations and simple stimulus configurations for all subjects.

The deleterious effects of short stimulus durations and long interstimulus delays were apparent in the present DNMTS study, as well as in the earlier DMTS study (Oscar-Berman \& Bonner, 1985). Both of these tasks require at least two memory components for accurate performance: memory for the rule of the task and memory for the information displayed immediately before the delay on each trial. The former has been referred to as procedural or semantic memory, and the latter has been termed declarative or episodic memory (Tulving, 1985). All of our subjects were capable of learning the tasks at hand; performance declined in some groups only under conditions that taxed their perceptual processing capacity as well as short-term storage. Thus, our results confirm other findings that semantic or procedural memory is not selectively impaired in human amnesia of alcohol-related etiology (Mishkin, Spiegler, Saunders, \& Malamut, 1982; Oscar-Berman, 1984; Zola-Morgan \& Squire, 1985). Rather, performance is compromised when there is insufficient time to view the stimuli to be recalled after a long delay. The results of the present study also confirm our observations that processing deficits occur with aging. The added characteristic of alcohol abuse compounds the effects of aging only in the most difficult experimental conditions (short durations and long delays), thus lending some support to the premature aging hypothesis of the effects of chronic alcoholism (Ellis \& Oscar-Berman, 1989; Oscar-Berman \& Pulaski, 1984; Pulaski \& OscarBerman, 1984; Ryan \& Butters, 1986).

Finally, the results of the present study provide data obtained from measures of human performance that are directly comparable to those used to assess cognitive deficits in brain-damaged monkeys (Freedman \& OscarBerman, 1986a, 1986b, 1986c; Oscar-Berman, 1980, 1984; Squire et al., 1988). Using DNMTS to examine memory impairments in monkeys, investigators have shown that deficits occur following bilateral damage to medial temporal or diencephalic structures (Aggleton \& Mishkin, 1983; Gaffan, Gaffan, \& Harrison, 1984; Ma- hut, Zola-Morgan, \& Moss, 1982; Mishkin, 1978; ZolaMorgan, Squire, \& Mishkin, 1982). Witt and GoldmanRakic (1983) also reported severe deficits on DNMTS tests in monkeys with an experimentally induced thiamine deficiency (an animal model of alcoholic Korsakoff's disease). The deficits were associated with brainstem lesions (e.g., raphe nuclei, midline tegmentum, the area between the trochlear nuclei, etc.). However, the affected brainstem regions are known to project to other brain structures, including cortical association regions, that are important for normal matching- and nonmatching-to-sample performance (Horel, 1978; Lhermitte \& Signoret, 1976; Mishkin, 1978; Oscar-Berman \& Bonner, 1985). Surprisingly, regions relatively spared by thiamine deprivation were the diencephalic structures (mammillary bodies of the hypothalamus and medial dorsal thalamic nuclei) and the medial temporal areas (hippocampus and amygdala) that typically are implicated in human amnesia.

Patients with diffuse cortical atrophy, characteristic of Alzheimer's disease, also have demonstrated DNMTS deficits (Albert \& Moss, 1984); since normal aging individuals were not tested in that study, however, the extent of their impairment is not known. However, on the basis of the pattern of the combined results of all studies mentioned so far, it may be that widespread cortical damage, either directly or as a secondary result of subcortical damage, is responsible for some aspects of the deficits on DNMTS tasks. Our own results with Ks and older normal and alcoholic groups are supportive of such a view, as is the evidence of Wilkinson and Carlen (1982), but future research with additional groups of neurological patients is warranted.

\section{REFERENCES}

Aggleton, J. P., \& Mishkin, M. (1983). Memory impairment following restricted medial thalamic lesions in monkeys. Experimental Brain Research, 52, 199-209.

ALBERT, M., \& Moss, M. (1984). The assessment of memory disorders in patients with Alzheimer's disease. In L. R. Squire \& N. Butters (Eds.), Neuropsychology of memory (pp. 236-246). New York: Guilford.

Arendt, T., Bigl, V., Arendt, A., \& Tennstedt, A. (1983). Loss of neurons in the nucleus basalis of Meynert in Alzheimer's disease. Acta Neurologica, 61, 101-108.

Butters, N. (1987). The continuity hypothesis: Some conclusions and their implications for the etiology and neuropathology of alcoholic Korsakoff's syndrome. In O. A. Parsons, N. M. Butters, \& P. Nathan (Eds.), Neuropsychology of alcoholism: Implications for diagnosis and treatment (pp. 176-206). New York: Guilford.

Cahalan, D., Cisin, I. H., \& Crossley, H. M. (1969). American drinking practices: $A$ national study of drinking behavior and attitudes (Monograph No. 6). New Brunswick, NJ: Rutgers University.

Elus, R. J., \& Oscar-Berman, M. (1989). Alcoholism, aging and functional cerebral asymmetries. Psychological Bulletin, 106, 128-147.

Freedman, M., \& OSCAR-Berman, M. (1986a). Bilateral frontal lobe disease and selective delayed-response deficits in humans. Behavioral Neuroscience, 100, 337-342.

Freedman, M., Oscar-Berman, M. (1986b). Comparative neuropsychology of cortical and subcortical dementia. Canadian Journal of Neurological Sciences, 13, 410-414.

Freedman, M., Oscar-Berman, M. (1986c). Selective delayed response deficits in Parkinson's and Alzheimer's disease. Archives of Neurology, 43, 886-890. 
Gaffan, D., Gaffan, E. A., \& Harrison, S. (1984). Effects of for nix transection on spontaneous and trained non-matching by monkeys. Quarterly Joumal of Experimental Psychology, 36B, 285-303.

Horel, J. A. (1978). The neuroanatomy of amnesia: A critique of the hippocampal memory hypothesis. Brain, 101, 403-445.

LhERMitTE, F., \& SignORET, J.-L. (1976). The amnesic syndrome and the hippocampal-mammillary system. In M. R. Rosenzweig \& E. L. Bennett (Eds.), Neural mechanisms of learning and memory (pp. 4956). Cambridge, MA: MIT Press.

MacVane, J., Butters, N., Montgomery, K., \& Farber, J. (1982). Cognitive functioning in men social drinkers. Journal of Studies on Alcoholism, 43, 81-95.

Mahut, H., Zola-Morgan, S. M., \& Moss, M. (1982). Hippocampal resections impair associative learning and recognition memory in the monkey. Journal of Neuroscience, 2, 1214-1229.

MAKI, W. S., \& LEITH, C. R. (1973). Shared attention in pigeons. Journal of the Experimental Analysis of Behavior, 19, 345-349.

Mishkin, M. (1978). Memory in monkeys severely impaired by combined but not separate removal of amygdala and hippocampus. $\mathrm{Na}$ ture, 273, 297-298.

Mishin, M., Spiegler, B. J., Saunders, R. C., \& Malamut, B. L. (1982). An animal model of global amnesia. In S. Corkin, K. L. Davis, J. W. Growdon, E. Usdin, \& R. J. Wurtman (Eds.), Alzheimer's disease: A report of progress in research (Aging, Vol. 19, pp. 235-247). New York: Raven.

NiAAA: Alcohol, Drug Abuse, and Mental Health AdministraTION. (1983). The fifth special report to the U.S. Congress on alcohol and health. Washington, DC: United States Department of Health and Human Services.

Oscar-Berman, M. (1980). Neuropsychological consequences of longterm chronic alcoholism. American Scientist, 68, 410-419.

OsCaR-BERman, M. (1984). Comparative neuropsychology and alcoholic Korsakoff's disease. In L. R. Squire \& N. Butters (Eds.), Neuropsychology of memory (pp. 194-202). New York: Guilford.

Oscar-Berman, M., \& BonNer, R. T. (1985). Matching and delayed matching-to-sample performance as measures of visual processing, selective attention, and memory in aging and alcoholic individuals. Neuropsychologia, 23, 639-651.

Oscar-Berman, M., \& Ellis, R. J. (1987). Cognitive deficits related to memory impairments in alcoholism. In M. Gallanter (Ed.), Recent developments in alcoholism (Vol. 5, pp. 59-80). New York: Plenum.

Oscar-Berman, M., Goodglass, H., \& Cherlow, D. G. (1973). Perceptual laterality and iconic recognition of visual materials by Korsakoff patients and normal adults. Journal of Comparative \& Physiological Psychology, 82, 316-321.

Oscar-Berman, M., \& Pulaski, J. L. (1984, August). Association memory in amnesia, alcoholism, and aging. Paper presented at the American Psychological Association Convention, Toronto, Ontario, Canada.
Oscar-Berman, M., \& Weinstein, A. (1985). Visual processing, memory and lateralization in alcoholism and aging. Developmental Neuropsychology, 1, 99-112.

Parsons, O. A. (1987). Neuropsychological consequences of alcohol abuse: Many questions-some answers. In O. A. Parsons, P. Nathan, \& N. Butters (Eds.), Neuropsychology of alcoholism: Implications for diagnosis and treatment (pp. 153-178). New York: Guilford.

Pulaski, J. L., \& Oscar-Berman, M. (1984, August). Recognition memory in amnesia, alcoholism, and aging. Paper presented at the American Psychological Association Convention, Toronto, Ontario, Canada.

RYAN, C., \& BUtTERs, N. (1986). Neuropsychology of alcoholism. In D. Wedding, A. M. Horton, \& J. S. Webster (Eds.), The neuropsychology handbook (pp. 376-409). New York: Springer.

Schlotterer, G., Moscovitch, M., \& Crapper-Mclachlan, D. (1984). Visual processing deficits as assessed by spatial frequency, contrast sensitivity and backward masking in normal ageing and Alzheimer's disease. Brain, 107, 309-325.

Squire, L. R., Zola-Morgan, S., \& Chen, K. S. (1988). Human amnesia and animal models of amnesia: Performance of amnesic patients on tests designed for the monkey. Behavioral Neuroscience, 102, 210-221.

TulviNG, E. (1985). How many memory systems are there? American Psychologist, 40, 385-398.

Warrington, E. K., \& WeISKrantz, L. (1974). The effect of prior learning on subsequent retention in amnesic patients. Neuropsychologia, 12, 419-428.

Wilkinson, D. A., \& CARLen, P. L. (1982). Morphological abnormalities in the brains of alcoholics: Relationship to age, psychological test scores and patient type. In W. G. Wood \& M. F. Elias (Eds.), Alcoholism and aging: Advances in research (pp. 61-77). Boca Raton, FL: CRC Press.

WINER, B. J. (1979). Statistical principles in experimental design. New York: McGraw-Hill.

WitT, E. D., \& Goldman-RaKiC, P. S. (1983). Intermittent thiamine deficiency in the rhesus monkey: 2. Evidence for memory loss. Annals of Neurology, 13, 396-401.

Zola-Morgan, S., \& SQUire, L. R. (1985). Medial temporal lesions in monkeys impair memory in a variety of tasks sensitive to amnesia. Behavioral Neuroscience, 99, 22-34.

Zola-Morgan, S., SQuire, L. R., \& Mishkin, M. (1982). The neuroanatomy of amnesia: Amygdala-hippocampus versus temporal stem. Science, 218, 1337-1339.

(Manuscript received June 10, 1987; revision accepted for publication May 18, 1989.) 